\title{
Sarbanes-Oxley, dynamic standard setting and the management of over-the-counter derivatives
}

\author{
John O. Matthews* and Cathy A. Rusinko \\ ${ }^{*}$ College of Commerce and Finance, Villanova University, 800 Lancaster Avenue, \\ Villanova, PA 19085, USA. Tel. +1 610519 4357; Fax. +1 610519 6881; E-mail: \\ John.Matthews@Villanova.edu
}

Received: 24th November, 2004

\begin{abstract}
John O. Matthews is an assistant professor of finance at Villanova University. He was a financial economist at the US Securities and Exchange Commission from 1977 to 1984 . His research interests are competition among securities firms, innovation in financial products and the economic and regulatory environment of the over-the-counter derivatives market. Dr Matthews is the author of 'Struggle and Survival on Wall Street: The Economics of Competition Among Securities Firms' (Oxford University Press, 1994) and other papers on technology and innovation in financial markets.
\end{abstract}

Cathy A. Rusinko is an assistant professor of management at Philadelphia University. Her research interests include management of innovation and technology, particularly in the financial services industry. She has worked at the US Department of Agriculture and General Electric Corporation. She has published numerous articles on innovation and technology and is interviewed by and quoted in the business press.

\section{Practical applications}

This paper reviews and explains the different types of standards for OTC derivatives, including those resulting from the Sarbanes-Oxley Act. The paper is, therefore, appropriate reading for financial managers, risk managers and non-financial managers. It is also appropriate reading for academics and students in finance, management and other business disciplines. Financial and risk managers can evaluate their own approaches relative to those that are currently used and available in the industry. In addition, they can ensure that they are staying up to date with all members of the technological community. Non-financial managers can gain a greater awareness of the current standard-setting framework with respect to over-the-counter (OTC) derivatives and the impact of Sarbanes-Oxley. Academics and students in finance, management and other business disciplines can get a better understanding of the relationship between risk management and the evolution and management of standards and standard-setting organisations, as applied to OTC derivatives.

Derivatives Use, Trading \& Regulation, Vol. 11 No. 1, 2005, pp. 75-87 Henry Stewart Publications, $1747-4426$

\section{Abstract}

Risk management using over-the-counter (OTC)

financial derivatives has become important for

many corporations. Despite the widespread use of

OTC derivatives, however, this market is not directly regulated in the US. Instead, trust is placed in the technological community which produces and improves these derivatives to ensure that the market operates effectively. The technological community includes private and 
public sector actors who create and support the infrastructure that develops and commercialises new derivatives technology and includes the standard-setting organisations for OTC derivatives. There are three types of standards in this market: (1) formal standards; (2) standards that emerge from best industry practice; and (3) guidance on treatment of OTC derivatives. Documents related to the Sarbanes-Oxley Act add to this standards framework by providing guidance on risk management and the treatment of derivatives. This paper suggests that risk managers be actively involved in this technological community in order to ensure that their firms are employing the most current OTC derivatives technology.

\section{INTRODUCTION}

The market for over-the-counter (OTC) financial derivatives has grown dramatically over the past 20 years and has become one of the world's most important financial markets. The market does not operate within a formal, governmental regulatory framework in the US, however. Rather, regulators have been willing to rely on the correcting, improving and standard-setting properties of the technological community that produces, trades and monitors this market to ensure that the market operates effectively.

Recent research in the management of technology area ${ }^{1}$ has described the process by which a technological community of stakeholders facilitates the development, commercialisation and improvement of a changing and improving product. Likewise, a technological community has emerged in the OTC derivatives area. This community transcends the boundaries of individual firms, industries and populations and includes public and private sector actors. One of the manifestations of this technological community is the set of standard-setting organisations that have emerged to facilitate improvements in derivatives. Rusinko and Matthews ${ }^{2}$ examined the emergence of this technological community in the OTC derivatives market.

An important new element has been added to the standard-setting framework for OTC derivatives with the introduction of the Sarbanes-Oxley Act (SOX) of 2002. This Act requires that firms put in place an internal control framework that provides comprehensive business controls and also assesses their effectiveness. The only internal control framework developed in the US that the Securities and Exchange Commission certifies meets the requirements of SOX is the framework developed by the Committee of Sponsoring Organizations (COSO) in $1992 .^{3}$ That information tool was initially developed to help end-users of financial derivatives to establish, assess and improve their internal control systems. In September 2004, COSO released the Enterprise Risk Management - Integrated Framework ${ }^{4}$ (ERM) to provide firms with integrating principles, common terminology and practical guidelines to develop or benchmark their enterprise risk management system. The effect of the SOX requirement of internal controls and the guidance provided by the COSO will, in the long run, provide a more standardised approach to internal 
controls and provide for more standardised disclosure of derivatives activities.

Standards for OTC derivatives, however, do not originate from one established standard-setting organisation. Rather, there are three ways in which standards are developed. First, standards are established by formal standard-setting organisations in both the public and private sectors. Secondly, various best practice standards emerge from the interaction of participants in the technological community through conferences, professional organisations and the regulatory examination process. These standards tend to ratify what has been going on in the marketplace. Thirdly, there is guidance which has been developed for corporate risk management activities. The guidance that emerged from SOX and its associated documents provides direction on how derivatives are to be treated within a firm.

Because of the rapid change and innovation in OTC derivatives, the standards are generally in a state of flux and, when some product or strategy becomes widely used in the industry, it also becomes part of the standards framework. Despite occasional calls for regulation of this market, US financial regulators have chosen not to put a formal regulatory system in place because of a belief that many of the problems that appear in the OTC derivatives market can be solved through the analytical, problem-solving and learning capabilities of the community that produces and trades derivatives.

This paper describes the dealers, end-users, standard-setting organisations, professional organisations, academics and regulators, and their interactions in this market. The activities of the standard-setting organisations, complemented by the consultative and oversight activities of the regulators, have allowed this market to grow at an incredible rate. The technological community has produced improvements in finance technology that have enabled financial and non-financial organisations to manage the risks associated with carrying hundreds of billions of dollars in financial assets on their balance sheets.

With SOX, there is more emphasis on risk management and the disclosure of risk management capabilities and approaches. In addition, financial analysts who evaluate the performance of firms are increasingly focusing on risk management as part of their analysis. So corporate risk managers must interact with members of the technological community in order to ensure that their risk management approaches are current and that the market recognises their level of risk management capability.

This paper describes the context of standard setting for this market and helps to explain why there does not appear to be a need for a complex regulatory structure for OTC derivatives in the US market. The paper describes the growth of the derivatives markets, the technological communities framework and the role that standard setters play in that community. Then it discusses the formal standards setters, the adoption of best practice technology and the importance of guidance for this market. Conclusions and recommendations follow. 


\section{GROWTH OF THE OTC DERIVATIVES MARKET}

Stulz $z^{5}$ reports on the growth of the market for OTC derivatives. The Bank for International Settlements (BIS) has conducted surveys of 60 major derivatives dealers since 1998. In June 2003, the total notional amount of OTC derivatives was $\$ 169.7$ trillion, up from $\$ 94$ trillion in June 2000. That represents an 80 per cent increase over those years.

The International Swaps and Derivatives Association (ISDA) publishes a longer series for notional amounts of currency swaps, interest rate swaps and interest rate options. In 1987, the notional amount of these derivatives was $\$ 865 \mathrm{bn}$. In 2003 , the ISDA reported a notional amount of $\$ 124$ trillion, indicating that the market grew at the rate of 36 per cent per year over the 16-year period.

\section{VAN DE VEN MODEL OF A TECHNOLOGICAL COMMUNITY}

Research in the management of technology area has established that a technological community must be involved in order for an innovation to emerge, be developed and marketed. In addition, an industrial infrastructure must be developed and evolve to facilitate ongoing improvements in technology. Van de Ven et al., ${ }^{1}$ building on earlier research, developed a framework of an industry that focuses on the relationships between key components of the industry infrastructure. The framework includes firms in the industry and also many other private and public actors who perform critical functions to develop, commercialise and improve a new technology. According to this view, an entire social system must develop to facilitate innovation. Also, importantly, institutional arrangements and technical change must co-evolve in order for innovative products and services to continue to evolve.

The Van de Ven framework identifies four interrelated components that are necessary for technological innovation.

These include: (1) institutional arrangements to legitimise, regulate and standardise a new technology; (2) public resource endowments of basic scientific knowledge, financing mechanisms and a pool of competent labour; (3) market mechanisms to educate consumers and stimulate demand for new technology; and (4) proprietary research and development and marketing functions by private firms to commercialise the innovation for profit. Rusinko and Matthews ${ }^{2}$ examined these components and how they interrelate in explaining the emergence of the OTC derivatives market's technological community.

\section{STANDARD SETTING WITHIN THE TECHNOLOGICAL COMMUNITY}

This paper focuses on the institutional arrangements that have evolved to provide standards for OTC derivatives. The large losses related to derivatives in the early and mid-1990s, incurred by such well-known firms as Procter \& Gamble and Barings Bank, prompted the expansion of standard-setting activities in this market. 
One of the ways in which firms

collectively create and maintain institutional legitimising devices is through the adoption of industry standards. Standards are developed through industry councils, technical committees and trade associations. ${ }^{6}$ These industry organisations, in turn, approach, educate and negotiate with other institutions and governmental units to obtain endorsements of these standards and the development of regulatory procedures.

In their examination of the economies of compatibility standards, David and Greenstein $^{7}$ defined standards as a set of technical specifications adhered to by a producer, either tacitly or as a result of a formal agreement. The setting of standards is a powerful institutional mechanism for reducing the many uncertainties of technological development by channelling the direction of resource investments and technological change. Hawkins et al. ${ }^{8}$ provide a definition of standards that most closely describes OTC derivatives standards. They state that standards can act as a codification of accumulated technical experience - as a baseline from which new technologies emerge.

David and Greenstein ${ }^{7}$ proposed a taxonomy for types of standards. OTC derivatives fall into two of their four categories as either (1) unsponsored standards - these being sets of specifications that have no identified originator holding a proprietary interest, nor any subsequent sponsoring agency but nevertheless exists in a well-documented form in the public domain - or (2) standards agreements arrived at within, and published by, voluntary standards-writing institutions.

\section{US REGULATORY APPROACH TO OTC DERIVATIVES}

\section{US Congress}

Congressman James A. Leach, Chairman of the Committee on Banking, Finance and Urban Affairs, argued that Congressional standard setting for OTC derivatives would be unrealistically imprudent. ${ }^{9}$ He observed that derivatives may be too sophisticated for a Congress of generalists to deal with legislatively. He expressed the view, however, that legislators should still expect sophistication from those parts of the executive branch charged with overseeing the financial markets. The analysis of this paper suggests that the regulators' sophistication should include an understanding of the operation of the technological community.

\section{Commodity Futures Modernisation Act of 2000}

The regulatory approach to OTC derivatives was specifically addressed by the Commodity Futures Modernisation Act of 2000. In November 1999, the President's Working Group on Financial Markets published its report on OTC derivatives and the Commodity Exchange Act (CEA). The Working Group concluded that OTC derivatives transactions should be subject to the CEA only if necessary to achieve the policy objectives of the Act - deterring market manipulation and protecting investors against fraud and other unfair practices. In the case of financial derivatives transactions involving professional counterparties, the Working Group concluded that regulation was unnecessary for these purposes because 
financial derivatives generally are not readily susceptible to manipulation and because professional counterparties can protect themselves against fraud and unfair practices. Therefore, the Working Group recommended that OTC derivatives transactions between professional counterparties be excluded from the coverage of the CEA. The treatment of OTC derivatives in the Commodity Futures Modernisation Act of 2000 is generally consistent with the Working Group's conclusion.

\section{Sarbanes-Oxley Act of $\mathbf{2 0 0 2}$}

Sarbanes-Oxley was passed in response to recent business scandals which found executives testifying that they were 'unaware' of questionable activities at their firms, such as improper revenue recognition and off the books partnerships. SOX is intended to reduce this possibility through a number of measures that strengthen internal checks and enhance accountability. SOX focuses on the critical role of internal controls.

Although SOX provides no explicit language about OTC derivatives, it contains a general requirement for an internal control system. This requirement can be met through the COSO framework.

Section 404 requires issuers to establish a formal internal controls system in accordance with a recognised framework. It requires securities issuers to include in their annual reports a report by management on the company's internal controls over financial reporting. The annual report must also include a statement that the registered public accounting firm that audited the statement has issued an attestation report on management's assessment of the company's internal controls. ${ }^{10}$ The Securities and Exchange Committee (SEC) stated that the internal controls framework developed by COSO satisfy the criteria for an acceptable framework.

Under SOX, there are no specific 'best-practice' recommendations to supplement COSO's framework. The absence of specific recommendations, under SOX, is a product both of the legislative necessity of language applicable to all who follow the law and the comprehensive nature of the response required to rectify the market breakdown. Also, the term 'internal controls' means different things to different people, which leads to difficulties when it is written into laws, rules and regulations. Therefore, many companies have adopted the COSO process-oriented approach to developing their own 'definition' of internal controls within the COSO framework.

\section{STANDARDS-SETTING FRAMEWORK FOR OTC DERIVATIVES}

Government regulators interact with other members of the technological community in the development of a framework of standards and practices for OTC derivatives. In some cases, regulators play a direct role in the development of these standards and, in other cases, regulators play a consultative role to private sector organisations.

The result of constant innovation in this dynamic market is that standards are developed in three ways. First, there are standard-setting organisations that develop 
formal standards for OTC derivatives.

These standards are developed in response to what is perceived widely as best industry practice and can represent choices among alternative industry practices.

Secondly, there are industry best practices that arise as improved products and strategies are used within the market and become well known. These are practices that derivatives professionals recognise as superior approaches, as they learn about them through professional organisations and other formal and informal networks. Competition through innovation is a primary form of rivalry among securities firms, and this type of competition exists in the OTC market among derivatives dealers. ${ }^{11}$

Thirdly, there are organisations that develop guidance to be used in risk management which often includes specific recommendations for the treatment of OTC derivatives. Guidance is used rather than specific standards because of the unique nature of the risk management issues faced by each firm. The lack of detailed guidance gives firms the opportunity to bring their own risk management perspective to their own firm's approach. Each of the three ways in which standards are developed is explained below.

\section{Formal standard-setting organisations}

Both private and public sector organisations have developed formal standards for OTC derivatives.

\section{International Swaps and Derivatives Association}

The ISDA is the industry's global trade association. It has more than 600 member institutions from 46 countries. Members include most of the world's major institutions who deal in OTC derivatives, as well as leading end-users of derivatives. The organisation was formed in New York in 1985 by a group of swap dealers and their counsels. In the early days of swap finance, each bank wrote its own wording for swap contracts. This lack of standardisation introduced costly delays into the approval of swap contracts and also introduced unnecessarily high legal expenses. Lack of standardisation also made it difficult for swap banks to match swaps and limited the secondary markets. In 1987, it published two suggested standard forms of master agreements for swaps (the 1987 ISDA Master

Agreements). Now market participants use what is referred to as the ISDA master, and negotiate a schedule which contains only those items that differ from the master.

The organisation continues to produce more master agreements designed for derivative products. The organisation also works to standardise operational practices, evolve best practice standards and publish best practice statements. In addition, it conducts seminars around the world, formulates position papers on issues important to its members, negotiates with regulators on behalf of its members and publishes important publications alongside the master agreements. ${ }^{6}$

\section{Futures and Options Association}

The Futures and Options Association in the UK performs many of the same functions as the ISDA. 


\section{Group of Thirty}

The Group of Thirty, which was formed in 1978 , is an international association of bankers and former government officials which attempts to parallel efforts of central bankers and other regulators to develop supervisory practices and capital requirements for banks.

In July 1993, the Group published 'Derivatives: Principles and Practices'. The study was the first comprehensive effort to take stock of what the industry has learned and to broaden awareness of the more successful management practices. It provided 20 recommendations for both dealers and end users. The recommendations were put together by a diverse cross-section of dealers, end-users, academics, accountants and lawyers involved in the derivatives business. Some of the recommendations reflected practices that were already in widespread use, others represented choices between alternative practices, while still others represented emerging practices followed by a handful of participants.

\section{Derivatives Policy Group}

This group was organised in 1994 by the leading investment banks on Wall Street to respond to the public policy issues raised by the OTC derivatives activities of unregulated affiliates of SEC registered broker dealers and Commodities Futures Trading Commission (CFTC) registered futures commission merchants. The group worked closely with the SEC and the CFTC in the preparation of a report. The group's report was issued in March 1995 and established a framework for voluntary oversight of the OTC derivatives activities of securities firm affiliates. The framework consisted of four interrelated components: management controls; enhanced reporting; evaluation of risk in relation to capital; and counterparty relationships. Under the framework, the SEC and the CFTC were to receive enhanced quantitative reports, estimates of capital at risk, stress scenario data with respect to core market risk factors and estimates of current and potential credit exposure from participating firms. ${ }^{6}$

\section{Counterparty Risk Management Group}

The Counterparty Risk Management Group was established in 1998 by a group of 12 major, internationally active commercial banks to address issues related to the near collapse of the Long Term Capital Management hedge fund. The firm's derivatives strategies played an important role in the firm's difficulties. The group provided recommendations to promote strong practices in counterparty credit and market risk management. The objectives of the group were endorsed by the Federal Reserve, the SEC and the Treasury Department. The groups' recommendations were built on the self-improvement efforts being undertaken by individual firms in the aftermath of the severe market disruptions in 1998, by evaluating and proposing improvements in market-wide practices and conventions in a collective manner, and by compiling information on best practices and, where appropriate, sharing that information with regulators. ${ }^{12}$

\section{Securities and Exchange Commission}

In 1997, the SEC issued Financial Reporting Release No. 48 (FRR48), 
'Qualitative and Quantitative Market Risk Disclosures', which requires firms to disclose both quantitative and qualitative market risk information. Market risk is defined by FRR48 as the risk of loss arising from adverse change in market rates and prices such as interest rates, foreign currency exchange rates, commodity prices and other relevant market rate or price changes.

The disclosure must be made by all SEC registrants as part of the 'Management's Discussion and Analysis' section in the annual Form 10-K report. The SEC issued FRR48 primarily in response to a perceived lack of information about firms' market risk, participation in hedging activities and derivatives use. Firms must also report qualitative information about particular risks and how they manage risk and account for derivatives.

\section{Financial Accounting Standards Board}

The Financial Accounting Standards Board (FASB) is a private sector organisation which functions as the accounting standard-setting organisation for the accounting profession. The SEC has formal oversight responsibilities for the FASB and consults closely with the FASB in the accounting standards-setting process.

In 1998, the FASB issued Statement of Financial Accounting Standards No. 133 (SFAS 133), 'Accounting for Derivatives Instruments and Hedging Activities'. Statement 133 requires that an enterprise report all of its derivatives as either assets or liabilities in its financial statements and measure those instruments at their fair market value. The statement generally requires that any change in the fair value of derivatives (gains or losses) be reported in the enterprise's earnings in the period charged. Several subsequent FASB releases extended SFAS 133.

\section{Basel Committee on Banking Supervision}

While there is no direct US regulation of OTC contracts or the operation of the market, there is a regulatory interest in the derivatives positions of US financial institutions. US financial regulators require that regulatory capital be adjusted for the risks associated with derivatives holdings. The regulatory adjustments have been developed in cooperation with bank regulators from other industrialised countries through the BIS.

The Basel Committee on Banking Supervision (BCBS) of the BIS was established by the G-10 central banks and provides a forum for regulatory cooperation among its member countries on banking supervisory matters. The BCBS formulates broad supervisory standards and guidelines and recommends statements of best practice in banking in the expectation that national bank supervisory authorities will take steps to implement them. US regulators play important roles on the BCBS committee and other BIS committees.

Under the BCBS 1998 approach, banks would use their own internal risk assessment models to assess their market risk. Banks would then report these risk measures to the regulators and set regulatory capital for market risk based partially on these numbers. This internal models approach allows banks a great deal of flexibility in developing their risk 
assessment technologies and enables

regulators to make use of the banks' expertise. The committee believes that improved risk management can be achieved by closely aligning bank capital requirements with prevailing risk management practices and by ensuring that this emphasis on risk-management practices makes its way into supervisory practices and into market discipline through risk- and capital-related disclosures. ${ }^{13}$

The BIS has also developed recommendations for settlement procedures and counterparty risk management for OTC derivatives. ${ }^{14}$

\section{Evolution of best industry practice}

New and improved products and strategies come from developers of derivatives and from the academic community. Of course, derivatives developers do not distribute their proprietary products and strategies freely to the market. Over time, however, successful products and strategies will be recognised in the market and become best industry practice.

\section{Interaction of firms and regulators through the examination process}

The Federal Reserve continuously evaluates the efforts banks make towards developing a forward-looking approach to risk management. Risk managers now have an expanding array of software, databases, models and rating systems which enable them to quantify and manage risk better than ever before. This increasing emphasis on risk control management has allowed bank examiners to shift their approach from evaluating financial results to understanding and assessing the quality of a bank's internal control process. The Fed's examination programme focuses on evaluating the overall adequacy of an institution's internal controls and risk management system as a benchmark against not only regulatory standards and expectations, but also against the evolving practices of well managed firms. ${ }^{15}$ Banks regulators have the advantage of access to numerous firms following different practices and so are able to develop a clear perspective on evolving best industry practices.

Regulators also share with other members of the technological community their insights into best industry practices, ${ }^{16}$ relying on market discipline through disclosure to ensure that firms are judged by the market for their performance in risk management.

\section{Professional organisations and the academic community}

Best practice information is shared in a variety of fora and educational and professional conferences. There is substantial cross-fertilisation, since many academics have worked for or consulted with large derivatives developers. Some academics make their analytical derivatives software available for free downloading from their websites.

One of the largest professional organisations, the International Association of Financial Engineers (IAFE), was established to discuss cutting edge issues in the field. The IAFE is composed of academics, practitioners, consultants, lawyers, regulators and accountants from 
financial and non-financial organisations throughout the world. The IAFE defines a core body of knowledge for the financial engineering profession. It aids in the distribution of best practice information among industry members, proposes industry standards and provides educational and networking opportunities.

Some of the other professional organisation and trade groups that play a role in the standard-setting process are The Bond Market Association, The Global Association of Risk Professionals and the London Investment Bankers Association.

\section{Guidance in the treatment of derivatives issues}

In the case of SOX and its related documents, the guidance is broadly based and relates to the overall risk management system. Since derivatives are integral to risk management, however, the documents address derivatives issues. Guidance for OTC derivatives is part of SOX-related documents.

\section{COSO and derivatives}

The COSO report, 'Internal Controls Integrated Framework', was issued in 1992. COSO states that this information tool was developed to help end-users of derivatives products establish, assess and improve internal control systems. The framework recognises that the nature and extent of derivatives use is frequently found in the overall risk management processes of an organisation. The report recommends that management evaluate the appropriateness of the risk management processes governing derivatives against the components of control specified in the COSO framework. In 1996, COSO extended its guidance for derivatives with the publication of 'Internal Controls in Derivatives Usage - An Information Tool'. ${ }^{17}$

\section{COSO's enterprise risk management framework}

The COSO provided additional guidance for risk management with its publication of 'Enterprise Risk Management - Integrated Framework' (ERM) in 2004. The intent of the framework is to develop a conceptually sound framework providing integrated principles, common terminology and practical implementation guidelines to support entities in the development or benchmarking of their enterprise risk management process. COSO states that a related objective is that the framework serve as a common basis for management, directors, regulators, academics and others to understand risk management, its benefits and limitations better, and to communicate effectively about risk issues.

The ERM framework takes a portfolio view of risk and encompasses: aligning risk appetite and strategy; enhancing risk response decisions; reducing operational surprises and losses; identifying and managing multiple and cross-enterprise risks; seizing opportunities; and improving deployment of capital. COSO argues that these capabilities are inherent in ERM and therefore they help management achieve the firm's performance and profitability targets.

COSO also makes the case that there are natural linkages between ERM, improved financial reporting and transparency. The 
framework introduces the concept of risk appetite and risk tolerance. It requires that organisations establish a risk appetite, measure actions against that risk appetite and communicate results. This framework is a broad framework which incorporates the internal controls framework within it. The frameworks are compatible and are based on the same conceptual framework.

COSO also notes that information used in risk management must be current and accurate and must be robust enough to support the analysis of different risk responses. Therefore, the technology that provides the data must have the highest level of integrity and controls. ERM will not be effective if the technology that provides the data used to manage risk are flawed. This can be interpreted to mean that firms must incorporate industry best practice in their risk management models.

The ERM discusses the role of members of the technological community outside the firm. It states that regulators may refer to this framework in establishing expectations, whether by rule or guidance, or in conducting examinations for entities they oversee. It also states that professional organisations providing guidance on financial management, auditing and related topics should consider their standards and guidance in light of this framework. COSO also expects that the framework will be the subject of academic research and analysis and eventually become part of university curricula.

\section{Software to implement SOX}

Numerous firms have developed software to help prepare SEC filers internal systems to comply with SOX. Software systems formalise controls, certifications, procedures and communications. The systems allow companies to collect, categorise and store information from a number of sources, identify the relevant response content, collaborate on risk issues and implement corrective mitigation processes. Some systems specifically integrate risk management into the control system. The software incorporates a firm's risk library, which is used as the basis of a firm's risk assurance activities. Pulling the risk libraries into the application gives the auditor a framework with which to attest to the effectiveness of internal controls. ${ }^{18}$

\section{CONCLUSION AND RECOMMENDATIONS}

The analysis in this paper suggests why there does not appear to be a strong demand for additional regulation of the OTC derivatives market in the US. Innovations in risk management technology are being managed by the technological community without substantial pressure for a more restrictive regulatory environment. Regulators play an active role in establishing standards and guidance for OTC derivatives and risk management. The institutional structure has developed to accommodate the advance of technology, with standards-setting organisations providing structure for this market.

With SOX, there is going to be more emphasis on disclosure and transparency for risk management. Financial analysts will be developing more metrics to judge the risk 
management performance of publicly traded firms. This suggests that the chief risk officer and other risk managers should be closely linked to the OTC derivatives technological community to ensure that their risk management approach reflects best industry practice. They should not only be aware of changes by formal standards-setting organisations, but also stay current with respect to best industry practices and less formal types of guidance. Also, directors and upper management should be aware of the importance of the firm keeping abreast of the technology through linkage with the technological community. Linkages can be achieved through membership in the standards-setting and professional organisations that focus on the distribution of best-practice industry information.

\section{References}

1 Van de Ven, A., Polley, D., Garud, R. and Venkataraman, S. (1999) 'The Innovation Journey', Oxford University Press, New York, NY.

2 Rusinko, C. A. and Matthews, J. O. (1997) 'Evolution of a Technological Community: A Case Study of Financial Derivatives', Journal of Engineering and Technology Management, Vol. 14, pp. 315-336.

3 Committee of Sponsoring Organizations (1992) 'Internal Controls — Integrated Framework', AICPA, New York, NY.

4 Committee of Sponsoring Organizations (2004) 'Enterprise Risk Management - Integrated Framework', AICPA, New York, NY.

5 Stulz, R. M. (2004) 'Should We Fear Derivatives', Ohio State University.

6 Rusinko, C. A. and Matthews, J. O. (1996) 'Standards Setting for Derivatives by the
Industry's Technological Community', Journal of Financial Engineering, Vol. 5, pp. 229-242.

7 David, P. A. and Greenstein, S. (1990) 'The Economics of Compatibility Standards: An Introduction to Recent Research', Economic Innovation and New Technology, Vol. 1, pp. 3-41.

8 Hawkins, R., Mansell, J. and Skea, J. (1995) 'The Politics and Economics of Standards in Natural and Technical Environments', Edward Elgar, Cheltenham, UK.

9 Leach, J. A. (1993) 'A Legislative Perspective on Derivatives', in 'Group of Thirty, Global Derivatives: Public Sector Responses', Occasional Paper 44, Washington, DC.

10 Deloitte \& Touche (2003) 'Moving Forward A Guide to Improving Corporate Governance Through Effective Internal Controls: A Response to Sarbanes-Oxley', New York, NY.

11 Matthews, J. O. (1994) 'Struggle and Survival on Wall Street: The Economics of Competition Among Securities Firms', Oxford University Press, New York, NY.

12 Matthews, J. O. and Rusinko, C. A. (2002) 'Regulation in the US OTC Derivatives Market: Toward a More Collaborative Framework', Derivatives Use, Trading and Regulation, Vol. 7, pp. 337-353.

13 Basel Committee on Banking Supervision (2004) 'Principles for the Management and Supervision of Interest Rate Risk', Basel, Switzerland.

14 Bank for International Settlements (1998) 'Report on OTC Derivatives: Settlement Procedures and Counterparty Risk Management', Basel, Switzerland.

15 Spillenkothen, R. (2002) 'Oversight of Investment Banks' Response to the Lessons of Enron', before the Permanent Committee on Investigations of the Committee on Government Affairs, US Senate, Washington, DC.

16 McDonough, W. J. (2003) 'Risk Supervision and the New Basel Accord', The Bond Market Association Legal and Compliance Conference, New York, NY, 4 February.

17 Committee of Sponsoring Organizations (1996) 'Internal Control Issues in Derivatives Usage An Information Tool', AICPA, New York, NY.

18 Goff, J. (2003) 'Sarboxing: CFOs Say Complying with Section 404 of Sarbanes-Oxley is a Real Tussle. Software May Help with the Struggle', www.CFO.com, accessed 10 June, 2004. 